\title{
Voltage Dependent LoAd In Power Flow ANALYSIS
}

\author{
Nitesh Kumar Lal ${ }^{1}$ and Dr. Samina Elyas Mubeen ${ }^{2}$ \\ ${ }^{1}$ Department of Electrical and Electronics Engineering, Radharaman Engineering College \\ Bhopal, India \\ ${ }^{2}$ Head of Department of Electrical and Electronics Engineering, Radharaman Engineering \\ College Bhopal, India
}

\begin{abstract}
Conventional load flow methods model the load at the buses as constant active and reactive powers. In actuality these can be constant current, constant impedance, constant power or any combination of these types of loads. In this paper attempt has been made to change the load flow mathematical formulation in order to incorporate the models of constant impedance and constant current type of load in addition to conventional constant power one at a time. The changed load flow formulation is tested on standard 5-bus system and the results are presented here.
\end{abstract}

\section{KEYWORDS}

Constant current loads, Constant impedance loads, Constant power loads, Voltage sensitive loads.

\section{INTRODUCTION}

The load flow studies are performed for power system planning, operation, and control. Load flow studies data are also used for contingency analysis, outage security assessment, as well as for optimal dispatching and stability. The load flow problem has received more attention than all the other power system problems combined. [1]

Load flow calculations provide power flow and voltage for a specified power system subjected to the regulating capability of generators, condensers and tap changing under load transformers as well as specified net interchange between individual operating system [2].

In conventional load flow studies, it is presumed that the active and reactive power demands are specified constant value, independent of the voltage value. Though in actuality, the various kind of residential, commercial and Industrial load demand active and reactive power which are functions of system voltage and frequency. This effects, if taken into account can cause major changes in the results of load flow and optimal power flow studies. Also the voltage dependence of system load largely affects the dynamic behaviour of a power system, and the impedance of its proper representation in power system stability studies has also been recognized [5].

The effects of voltage and frequency on active and reactive power loads have been studied by several researchers for some time [3-19]. The literature on the incorporation of load models in load flow studies is limited to only a few studies [4-6, 10, 20-22]. It has been shown that load modelling has significant effects for some systems [21].

DOI : 10.14810/elelij.2015.4206 
Frequency deviation is considered insignificant in case of static analysis like, load flow studies. The effects of voltage deviations are mainly taken into account for getting faster and accurate results. In recent year, much effort has been devoted to load modeling and the evaluation of model parameters through field measurements [6].

Few studies have been done on incorporating load modeling in load-flow algorithms. The literature is limited to two studies done by El-Hawary [23] and Murty [24]. The first study proposes a generalised nonlinear model for which $P=\mathrm{I} * j V b J$ but does not discuss the practical details involved in the evaluation of the proposed parameters. Murty considers an exponential model with applications to a 5-bus system, which proposed the alteration of the power equations to incorporate the effect of Varing load models. This consequently changed the Jacobian Matrix of the N-R Algorithm.

In some studies done on load modelling by Ontario Hydro [5, 6] some aspects of load flow have also been considered briefly. Some other literature available on web is based on the similar concept as 1 and 2 and the simulation is carried out using software like ETAP and others. However, the user-defined power flow software do not allow users to directly modify the Jacobian matrix and only provide the facilities for the iteration between the main program and the user defined model. This iteration sometimes diverges, especially when the system is heavily loaded or ill-conditioned.

The objective here is to study the behaviour of the load-flow solution when load models are incorporated using MATLAB programming. The code developed is generalized such that it can solve any number of bus systems at a time. It also gives the flexibility to change the type of the loads at the buses and to compare results with the conventional load-flow results. Available loadflow data and some available model parameters of a particular model are used in this study.

\section{Power Flow Formulation With Voltage Sensitive Loads}

The exponential model for representating the dependence of active power $(\mathrm{P})$ and reactive power (Q), on the bus voltage magnitude at a load bus in an electric power network takes the following form,

$$
\begin{aligned}
& \Delta P_{i}^{*}=\left(Q_{i}-Q_{i}^{S P}\right)\left(v_{i}\right)^{b}=0 \\
& Q_{i}^{*}=Q_{i(n)}\left(\frac{v_{i}}{v_{i(n)}}\right)^{b}
\end{aligned}
$$

The coefficient $P_{i(n)}$ and $Q_{i(n)}$ represents the active and reactive powers at nominal voltage $v_{i(n)}$. An alternate form of equation (1) and (2) can be written as

$$
\begin{aligned}
& P_{i}^{*}=P_{i}\left(v_{i}\right)^{a} \\
& Q_{i}^{*}=Q_{i}\left(v_{i}\right) b
\end{aligned}
$$

Where $V_{i}$ is the voltage in per unit base voltage taken as $V_{i(n)}$ 
Electrical and Electronics Engineering: An International Journal (ELELIJ) Vol 4, No 2, May 2015

In conventional load flow studies the $2 \mathrm{n}-1$ equations normally solved are:

$$
\begin{gathered}
\Delta \mathrm{P}_{\mathrm{i}}=\mathrm{P}_{\mathrm{i}}-\mathrm{P}_{\mathrm{i}}^{\mathrm{Sp}}=0 \quad \text { for } i=2, \ldots \ldots \ldots, \mathrm{n} \\
\Delta \mathrm{Q}_{\mathrm{i}}=\mathrm{Q}_{\mathrm{i}}-\mathrm{Q}_{\mathrm{i}}^{\mathrm{sp}}=0 \quad \text { for } i=\mathrm{m}+1, \ldots \ldots, \mathrm{n}
\end{gathered}
$$

Where;

$$
\begin{aligned}
& P_{i}=V_{i} \sum_{i=1}^{n} V_{j} Y_{i j} \operatorname{Cos}\left(\theta_{i}-\theta_{j}\right) \\
& Q_{i}=V_{i} \sum_{i=1}^{n} V_{j} Y_{i j} \operatorname{Sin}\left(\theta_{i}-\theta_{j}\right)
\end{aligned}
$$

$\mathrm{m}=$ number of generator buses including the swing bus $\mathrm{n}=$ total number of buses

The set of load equation (7) \& (8) are non-linear and solved by Newton Raphson iterative method which requires finding a jacobian matrix to update the current estimates of improved solutions. Since instead of constant specified powers, model of the form as in equations (3) and (4) are used, then equation (5) \& (6) change to

$$
\begin{aligned}
& \Delta \mathrm{P}_{\mathrm{i}}=\left(\mathrm{P}_{\mathrm{i}}-\mathrm{P}_{\mathrm{i}}^{\mathrm{SP}}\right)\left(\mathrm{V}_{\mathrm{i}}\right)^{\mathrm{a}}=0 \quad \text { for } i=2, \ldots, \mathrm{n} \\
& \Delta \mathrm{Q}_{\mathrm{i}}=\left(\mathrm{Q}_{\mathrm{i}}-\mathrm{Q}_{\mathrm{i}}^{\mathrm{SP}}\right)\left(\mathrm{V}_{\mathrm{i}}\right)^{\mathrm{b}}=0 \quad \text { for } i=\mathrm{m}+1, . ., \mathrm{n}
\end{aligned}
$$

Let the equations (9) \& (10) be denoted as $\Delta \mathrm{P}_{\mathrm{i}}^{*}$ and $\Delta \mathrm{Q}_{\mathrm{i}}^{*}$. In conventional Newton Raphson algorithm the matrix vector relationship between the changes in real and reactive powers and the bus voltages and angle are represented as,

Where,

$$
\begin{aligned}
& {\left[\Delta \mathrm{P}_{\mathrm{i}}\right]=\left[\partial \mathrm{P}_{\mathrm{i}} / \partial \theta_{\mathrm{i}}\right] \cdot\left[\Delta \theta_{\mathrm{i}}\right]+\left[\partial \mathrm{P}_{\mathrm{i}} / \partial \mathrm{V}_{\mathrm{i}}\right] \cdot\left[\Delta \mathrm{V}_{\mathrm{i}}\right]} \\
& {\left[\Delta \mathrm{Q}_{\mathrm{i}}\right]=\left[\partial \mathrm{Q}_{\mathrm{i}} / \partial \theta_{\mathrm{i}}\right] \cdot\left[\Delta \theta_{\mathrm{i}}\right]+\left[\partial \mathrm{Q}_{\mathrm{i}} / \partial \mathrm{V}_{\mathrm{i}}\right] \cdot\left[\Delta \mathrm{V}_{\mathrm{i}}\right]}
\end{aligned}
$$

$$
\begin{gathered}
{\left[\Delta \mathrm{P}_{\mathrm{i}}\right]=\left[\Delta \mathrm{P}_{2} \ldots \Delta \mathrm{P}_{\mathrm{n}}\right]^{\mathrm{T}}} \\
{\left[\Delta \mathrm{Q}_{\mathrm{i}}\right]=\left[\Delta \mathrm{Q}_{2} \ldots \Delta \mathrm{Q}_{\mathrm{n}}\right]^{\mathrm{T}}} \\
{\left[\Delta \theta_{\mathrm{i}}\right]=\left[\Delta \theta_{2} \ldots \Delta \theta_{\mathrm{n}}\right]^{\mathrm{T}}} \\
{\left[\Delta \mathrm{V}_{\mathrm{i}}\right]=\left[\Delta \mathrm{V}_{2} \ldots \Delta \mathrm{V}_{\mathrm{n}}\right]^{\mathrm{T}}} \\
{\left[\partial \mathrm{P}_{\mathrm{i}} / \partial \theta_{\mathrm{i}}\right]=\left[\partial \mathrm{P}_{2} / \partial \theta_{2} \ldots \partial \mathrm{P}_{\mathrm{n}} / \partial \theta_{\mathrm{n}}\right]^{\mathrm{T}}} \\
{\left[\partial \mathrm{P}_{\mathrm{i}} / \partial \mathrm{v}_{\mathrm{i}}\right]=\left[\partial \mathrm{P}_{2} / \partial \mathrm{v}_{2} \ldots \partial \mathrm{P}_{\mathrm{n}} / \partial \mathrm{v}_{\mathrm{n}}\right]^{\mathrm{T}}} \\
{\left[\partial \mathrm{Q}_{\mathrm{i}} / \partial \theta_{\mathrm{i}}\right]=\left[\partial \mathrm{Q}_{2} / \partial \mathrm{v}_{2} \ldots \partial \mathrm{Q}_{\mathrm{n}} / \partial \mathrm{v}_{\mathrm{n}}\right]^{\mathrm{T}}}
\end{gathered}
$$

Where bus 1 is the slack bus and the jacobian sub matrix are: 
Electrical and Electronics Engineering: An International Journal (ELELIJ) Vol 4, No 2, May 2015

$$
\begin{array}{ll}
\mathrm{J}_{1}=\left[\partial \mathrm{P}_{\mathrm{i}} / \partial \theta_{\mathrm{i}}\right], & \mathrm{J}_{2}=\left[\partial \mathrm{P}_{\mathrm{i}} / \partial \mathrm{V}_{\mathrm{i}}\right] \\
\mathrm{J}_{3}=\left[\partial \mathrm{Q}_{\mathrm{i}} / \partial \theta_{\mathrm{i}}\right], & \mathrm{J}_{4}=\left[\partial \mathrm{Q}_{\mathrm{i}} / \partial \mathrm{V}_{\mathrm{i}}\right]
\end{array}
$$

When voltage dependent loads are considered, the powers $P_{i}$ and $Q_{i}$ will change to $\mathrm{P}_{\mathrm{i}}^{*}$ and $\mathrm{Q}_{\mathrm{i}}^{*}$ as in equation (3) and (4). This change the jacobian elements of the jacobian with voltage dependent loads are derived from the bus power equation (3) and (4).

Differentiating (3) the diagonal elements of $\mathrm{J}_{2}$ are

but

$$
\frac{\partial P_{i}^{*}}{\partial V_{i}}=P_{i}(n) \cdot a \cdot V_{i}^{a-1}+\frac{\partial P_{i}(n)}{\partial V_{i}} V_{i}^{a}
$$

$$
\frac{\partial \mathrm{P}_{\mathrm{i}(\mathrm{n})}}{\partial \mathrm{V}_{\mathrm{i}}}=2 \mathrm{~V}_{\mathrm{i}} \mathrm{Y}_{\mathrm{ii}} \operatorname{Cos} \theta_{\mathrm{ii}}-\sum_{\substack{\mathrm{k}=1 \\ \mathrm{k}^{1 \mathrm{i}}}}^{\mathrm{n}} \mathrm{V}_{\mathrm{i}} \mathrm{Y}_{\mathrm{ik}} \operatorname{Cos}\left(\theta_{\mathrm{i}}-\theta_{\mathrm{k}}\right)
$$

hence

$$
\frac{\partial P_{i}^{*}}{\partial V_{i}}=a \cdot P_{i(n)} \cdot v_{i}^{a-1}+\left\{2 V_{i} Y_{i i} \operatorname{Cos} \theta_{i i}-\sum_{\substack{k=1 \\ k \neq i}}^{n} V_{i} Y_{i k} \operatorname{Cos}\left(\theta_{i}-\theta_{k}\right)\right\} v_{i}^{a}
$$

The off- diagonal element of $\mathrm{J}_{2}$ will be

$$
\frac{\partial P_{i}^{*}}{\partial v_{j}}=\frac{\partial P_{i}(n)}{\partial v_{j}} v_{i}^{a}
$$

Similarly differentiating equation (4) the diagonal elements of $\mathrm{J}_{4}$ are

$$
\begin{gathered}
\frac{\partial Q_{i}^{*}}{\partial V_{i}}=Q_{i(n)} \cdot b \cdot v_{i}^{b-1}+\frac{\partial Q_{i(n)}}{\partial V_{i}} V_{i}^{b} \text { but } \\
\frac{\partial Q_{i(n)}}{\partial V_{i}}=-2 V_{i} Y_{i i} \operatorname{Sin} \theta_{i i}+\sum_{\substack{k=1 \\
k \neq i}}^{n} V_{i} Y_{i k} \operatorname{Sin}\left(\theta_{i}-\theta_{k}\right)
\end{gathered}
$$

So,

$$
\frac{\partial Q_{i}^{*}}{\partial V_{i}}=b \cdot P_{i(n)} \cdot V_{i}^{b-1}-\left\{2 V_{i} Y_{i i} \operatorname{Sin} \theta_{i i}+\sum_{\substack{k=1 \\ k \neq i}}^{n} V_{i} Y_{i k} \operatorname{Sin}\left(\theta_{i}-\theta_{k}\right)\right\} V_{i}^{b}
$$

And the off-diagonal element of $\mathrm{J}_{4}$ are

$$
\frac{\partial Q_{i}^{*}}{\partial v_{j}}=\frac{\partial Q_{i(n)}}{\partial V_{j}} V_{i}^{b}
$$


The diagonal and off diagonal terms of $\mathrm{J}_{1}$ are

$$
\frac{\partial \mathrm{P}_{\mathrm{i}}^{*}}{\partial \theta_{\mathrm{i}}}=\frac{\partial \mathrm{P}_{\mathrm{i}(\mathrm{n})}}{\partial \theta_{\mathrm{i}}} \mathrm{V}_{\mathrm{i}}^{\mathrm{a}} \text { and } \frac{\partial \mathrm{P}_{\mathrm{i}}^{*}}{\partial \theta_{\mathrm{j}}}=\frac{\partial \mathrm{P}_{\mathrm{i}(\mathrm{n})}}{\partial \theta_{\mathrm{j}}} \mathrm{V}_{\mathrm{i}}^{\mathrm{a}} \text { respectively. }
$$

Similarly the diagonal and off diagonal term of $\mathrm{J}_{3}$ are

$$
\frac{\partial Q_{i}^{*}}{\partial \theta_{i}}=\frac{\partial Q_{i(n)}}{\partial \theta_{i}} V_{i}^{b} \text { and } \frac{\partial Q_{i}^{*}}{\partial \theta_{j}}=\frac{\partial Q_{i(n)}}{\partial \theta_{j}} V_{i}^{b} \text { respectively. }
$$

The estimated bus voltages and powers are used to evaluate the elements of jacobian, and then the new estimates for the bus voltage are

$$
\begin{gathered}
\theta_{i}^{\mathrm{k}+1}=\theta_{\mathrm{i}}^{\mathrm{k}}+\Delta \theta_{\mathrm{i}}^{\mathrm{k}} \\
\mathrm{v}_{\mathrm{i}}^{\mathrm{k}+1}=\mathrm{V}_{\mathrm{i}}^{\mathrm{k}}+\Delta \mathrm{V}_{\mathrm{i}}^{\mathrm{k}}
\end{gathered}
$$

The process is repeated until $\Delta \mathrm{P}_{\mathrm{i}}^{*}$ and $\Delta \mathrm{Q}_{\mathrm{i}}^{*}$ for all buses are within a specified tolerance. The line flows can be calculated with the final bus voltages, the given values of line charging and line admittances.

\section{TEST CASE AND SIMULATION}

Standard 14 bus test network is used to analyze the different types of load models at the buses. The codes are developed in MATLAB. The value of exponential parameters a and $b$ for the active and reactive powers, that represents the constant current, constant power loads, constant impedance loads are give in table 1 .

Table 1 Load type and exponent values

\begin{tabular}{|c|c|c|c|}
\hline \multirow{2}{*}{ S.NO } & Type of Load & \multicolumn{2}{|c|}{ Range of Exponent } \\
\cline { 3 - 4 } & & Active power (a) & Reactive Power (b) \\
\hline 1 & Constant Power Loads & 0 & 0 \\
\hline 2 & Constant Current Loads & 1 & 1 \\
\hline 3 & Constant Impedance Loads & 2 & 2 \\
\hline
\end{tabular}

Newton Raphson Power flow algorithm:

It consists of following steps.

1. Form the bus admittance matrix.

2. Assume bus voltages.

3. Set Iteration count $\mathrm{C}=0$

Calculate Bus Powers and Power mismatch $\Delta \mathrm{P}, \Delta \mathrm{Q} \Delta \mathrm{f} \Delta \mathrm{g}$ 
Electrical and Electronics Engineering: An International Journal (ELELIJ) Vol 4, No 2, May 2015

If the mismatch is less than the given tolerance, output the result else go to 5 .

4. Calculate the Bus Currents and the elements of Jacobian matrix and find the Voltage corrections Vector

5. Update the Voltage, increment the counter.

6. Go to step 4 .

Test Data of 14-bus system is given in table 2, 3 .

Table 2 Bus Data

\begin{tabular}{|c|c|c|c|c|c|c|}
\hline \multirow{3}{*}{ Bus No } & \multicolumn{2}{|c|}{ BUS VOLTAGE } & \multicolumn{2}{c|}{ GENERATOR } & \multicolumn{2}{c|}{ LOAD } \\
\cline { 2 - 7 } & $\begin{array}{c}\text { Voltage } \\
\text { magnitude(pu) }\end{array}$ & $\begin{array}{c}\text { Phase angle } \\
(\mathrm{deg})\end{array}$ & $\begin{array}{c}\text { MV, } \\
\text { MVR) }\end{array}$ & Qmin, Qmax & P(MW) & Q(MVAR) \\
\hline 1 & 1.06 & 0 & $0.4,0$ & $-0.4,0.5$ & 0.21 & 0.0 \\
\hline 2 & 1.045 & 0 & 0,0 & $0,0.4$ & 0.94 & 0.127 \\
\hline 3 & 1.010 & 0 & 0,0 & $-0.06,0.24$ & 0.47 & 0.19 \\
\hline 4 & 1 & 0 & 0,0 & $-0.06,0.24$ & 0.076 & 0.039 \\
\hline 5 & 1 & 0 & 0,0 & 0,0 & 0.11 & 0.075 \\
\hline 6 & 1 & 0 & 0,0 & 0,0 & 0.0 & 0.0 \\
\hline 7 & 1 & 0 & 0,0 & 0,0 & 0.0 & 0.0 \\
\hline 8 & 1 & 0 & 0,0 & 0,0 & 0.295 & 0.166 \\
\hline 9 & 1 & 0 & 0,0 & 0,0 & 0.09 & 0.058 \\
\hline 10 & 1 & 0 & 0,0 & 0,0 & 0.035 & 0.018 \\
\hline 11 & 1 & 0 & 0,0 & 0,0 & 0.061 & 0.016 \\
\hline 12 & 1 & 0 & 0,0 & 0,0 & 0.135 & 0.058 \\
\hline 13 & 1 & 0 & 0,0 & 0,0 & 0.149 & 0.05 \\
\hline 14 & 1 & 0 & 0,0 & 0,0 & 0.0 & 0.0 \\
\hline
\end{tabular}

Table 3 Line data

\begin{tabular}{|c|c|c|c|c|c|}
\hline $\begin{array}{l}\text { Transmission } \\
\text { Line }\end{array}$ & $\begin{array}{l}\text { Sending } \\
\text { Bus }\end{array}$ & $\begin{array}{l}\text { Receiving } \\
\text { Bus }\end{array}$ & $\begin{array}{l}\text { Line } \\
\text { resistance } \\
(\mathbf{p u})\end{array}$ & $\begin{array}{l}\text { Line } \\
\text { reactance } \\
(\mathbf{p u})\end{array}$ & $\begin{array}{l}\text { Line } \\
\text { suseptance } \\
\text { (pu) }\end{array}$ \\
\hline 1 & 1 & 2 & 0.01938 & 0.05917 & 0.0528 \\
\hline 2 & 2 & 3 & 0.08 & 0.24 & 0.0438 \\
\hline 3 & 2 & 4 & 0.06 & 0.18 & 0.0492 \\
\hline 4 & 1 & 5 & 0.06 & 0.18 & 0.034 \\
\hline 5 & 2 & 5 & 0.04 & 0.12 & 0.0346 \\
\hline 6 & 3 & 4 & 0.01 & 0.03 & 0.0128 \\
\hline 7 & 4 & 5 & 0.08 & 0.24 & 0.0 \\
\hline 8 & 5 & 6 & 0.02 & 0.06 & 0.0 \\
\hline 9 & 4 & 7 & 0.08 & 0.24 & 0.0 \\
\hline 10 & 7 & 8 & 0.06 & 0.18 & 0.0 \\
\hline 11 & 4 & 9 & 0.06 & 0.18 & 0.0 \\
\hline 12 & 7 & 9 & 0.04 & 0.12 & 0.0 \\
\hline 13 & 9 & 10 & 0.01 & 0.03 & 0.0 \\
\hline 14 & 6 & 11 & 0.08 & 0.24 & 0.0 \\
\hline 15 & 6 & 12 & 0.02 & 0.06 & 0.0 \\
\hline
\end{tabular}


Electrical and Electronics Engineering: An International Journal (ELELIJ) Vol 4, No 2, May 2015

\begin{tabular}{|l|c|c|c|c|c|}
\hline 16 & 6 & 13 & 0.08 & 0.24 & 0.0 \\
\hline 17 & 9 & 14 & 0.06 & 0.18 & 0.0 \\
\hline 18 & 10 & 11 & 0.06 & 0.18 & 0.0 \\
\hline 19 & 12 & 13 & 0.04 & 0.12 & 0.0 \\
\hline 20 & 13 & 14 & 0.01 & 0.03 & 0.0 \\
\hline
\end{tabular}

\section{RESULTS OF LOAD FLOW CALCULATION WITH VOLTAGE SENSITIVE LOADS}

The test network is tested first with Conventional load flow. Then it is analyzed with voltage sensitive loads at each of the bus.

For constant power load the convergence is achieved in 6 iteration while for constant current types of loads the convergence is in 9 iteration and for constant impedance type of loads it is 10 iteration with standard 14-bus system. The simulation yield the Bus Active and Reactive power flow with constant power, constant current and constant impedance loads as shown in Fig.1-2 respectively.

Voltages at the buses with different types of loads are given in table 4, 5, 6 .

Line active and reactive power flow with constant power, constant current and constant impedance loads as shown in Fig. 3-4 respectively.

The simultaneous yield Active and Reactive power losses in the transmission line with constant power, constant current and constant impedance loads as shown in Fig. 5-6 respectively.

Active power at bus is minimum for constant impedance type of load and maximum for constant power type of load. But at bus 4 active power for constant power type of load is less as compared to the constant impedance type of load.

Also Reactive power at bus is minimum for constant power type of load and maximum for constant impedance type of load.

Active and reactive power at line is maximum for constant power type of load and minimum for constant impedance type of load.

Active and reactive power losses at line are maximum for constant power type of load and minimum for constant impedance type of load. 
Electrical and Electronics Engineering: An International Journal (ELELIJ) Vol 4, No 2, May 2015

Table 4 Voltage at the buses with constant power Loads

\begin{tabular}{|c|c|c|}
\hline \multirow{2}{*}{ Bus No } & \multicolumn{2}{|c|}{ Bus Voltage } \\
\cline { 2 - 3 } & $1 \mathbf{V}$ | \\
\hline 1 & 1.06 & 0 \\
\hline 2 & 1.045 & -4.9403 \\
\hline 3 & 1.0150 & -12.9616 \\
\hline 4 & 1.0427 & -11.8381 \\
\hline 5 & 1.07 & -7.6192 \\
\hline 6 & 1.0525 & -8.9013 \\
\hline 7 & 1.09 & -11.4871 \\
\hline 8 & 1.0464 & -12.1690 \\
\hline 9 & 1.0479 & -10.8432 \\
\hline 10 & 1.0572 & -10.7110 \\
\hline 11 & 1.0674 & -9.9262 \\
\hline 12 & 1.0621 & -9.1099 \\
\hline 13 & 1.0598 & -9.5302 \\
\hline 14 & & -9.7154 \\
\hline
\end{tabular}

Table 5 Voltage at the buses with constant current Loads

\begin{tabular}{|c|c|c|}
\hline \multirow{2}{*}{ Bus No } & \multicolumn{2}{|c|}{ Bus Voltage } \\
\cline { 2 - 3 } & |VI & $\boldsymbol{\theta}$ \\
\hline 1 & 1.06 & 0 \\
\hline 2 & 1.045 & -4.8521 \\
\hline 3 & 1.01 & -12.744 \\
\hline 4 & 1.0154 & -11.636 \\
\hline 5 & 1.0455 & -7.4861 \\
\hline 6 & 1.07 & -8.7104 \\
\hline 7 & 1.0527 & -11.285 \\
\hline 8 & 1.09 & -11.964 \\
\hline 9 & 1.0466 & -10.645 \\
\hline 10 & 1.0481 & -10.513 \\
\hline 11 & 1.0574 & -9.7313 \\
\hline 12 & 1.0674 & -8.9182 \\
\hline 13 & 1.0622 & -9.3368 \\
\hline 14 & 1.0599 & -9.5213 \\
\hline
\end{tabular}


Electrical and Electronics Engineering: An International Journal (ELELIJ) Vol 4, No 2, May 2015

Table 6 Voltage at the buses with constant impedance Loads

\begin{tabular}{|c|c|c|}
\hline \multirow{2}{*}{ Bus No } & \multicolumn{2}{|c|}{ Bus Voltage } \\
\cline { 2 - 3 } & $\mathbf{| V |}$ & $\boldsymbol{\theta}$ \\
\hline 1 & 1.06 & 0 \\
\hline 2 & 10.45 & -4.7682 \\
\hline 3 & 1.01 & -12.537 \\
\hline 4 & 1.0156 & -11.442 \\
\hline 5 & 1.046 & -7.3257 \\
\hline 6 & 1.07 & -8.5349 \\
\hline 7 & 1.0528 & -11.095 \\
\hline 8 & 1.09 & -11.772 \\
\hline 9 & 1.0467 & -10.458 \\
\hline 10 & 1.0482 & -10.327 \\
\hline 11 & 1.0574 & -9.5498 \\
\hline 12 & 1.0674 & -8.7415 \\
\hline 13 & 1.0622 & -9.1577 \\
\hline 14 & 1.06 & -9.3411 \\
\hline
\end{tabular}

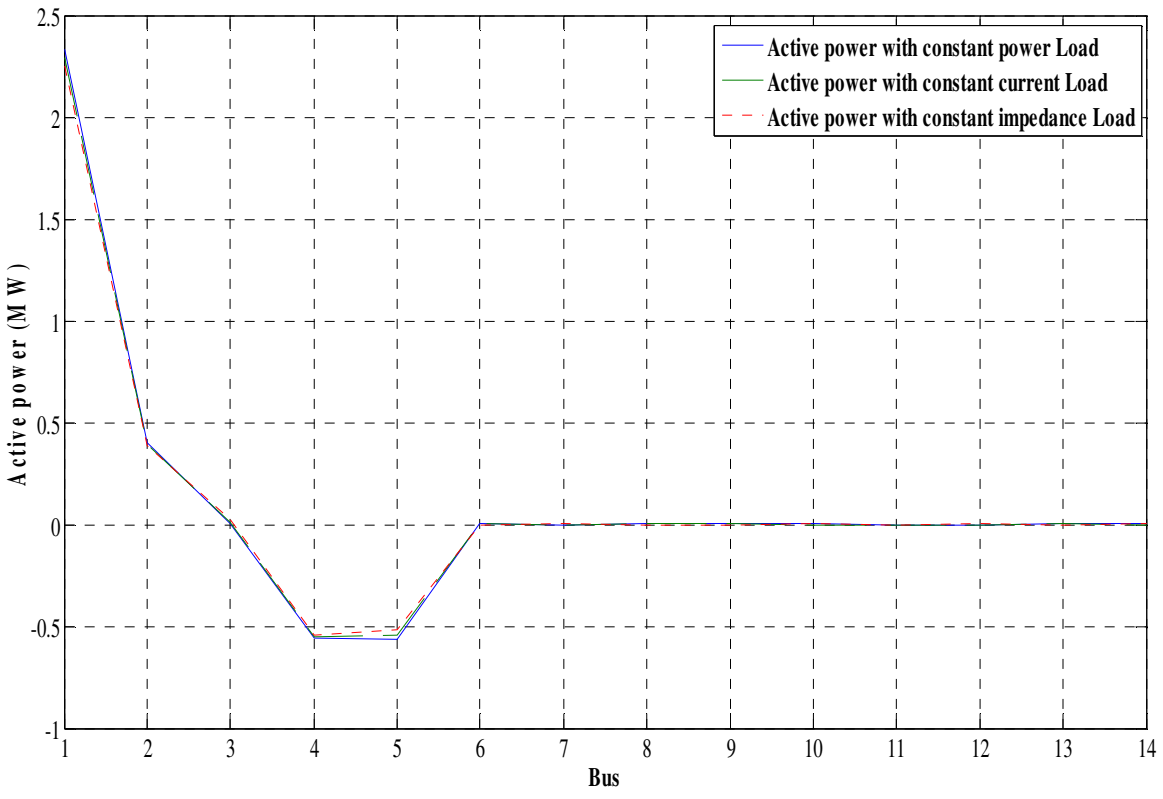

Figure.1. Active Power at Buses 
Electrical and Electronics Engineering: An International Journal (ELELIJ) Vol 4, No 2, May 2015

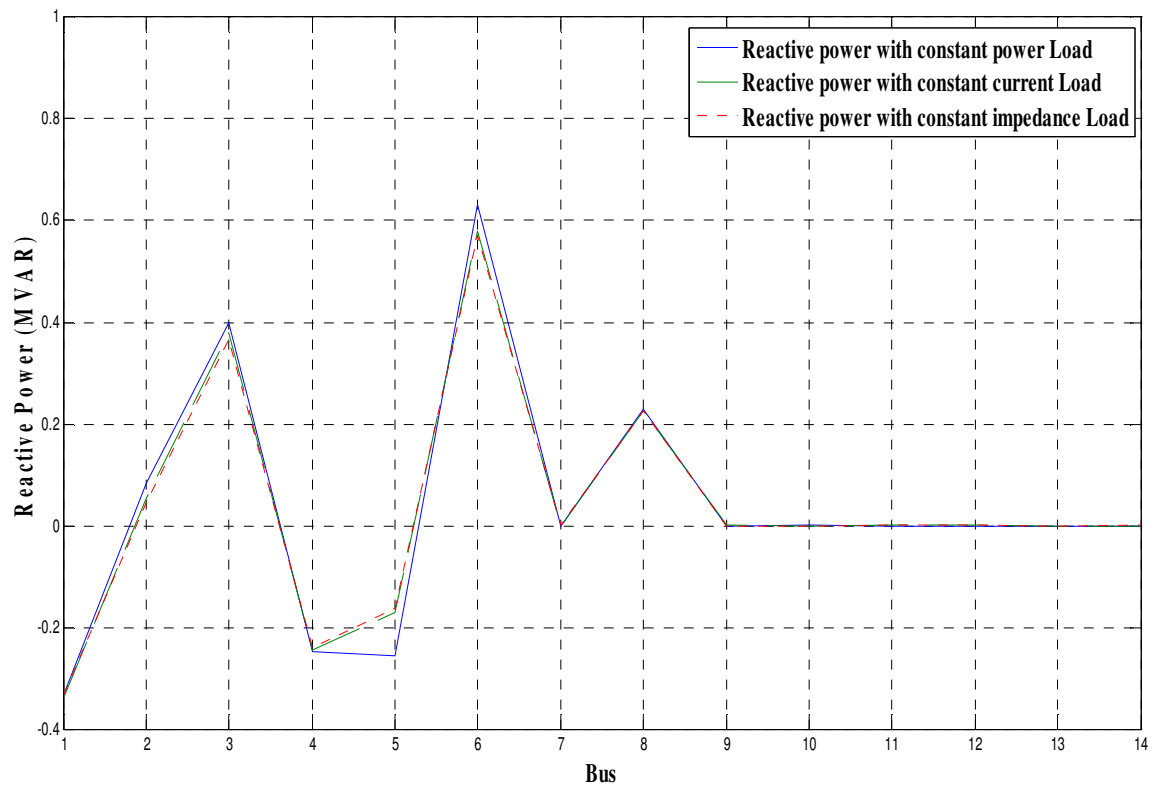

Figure 2. Reactive power at Buses

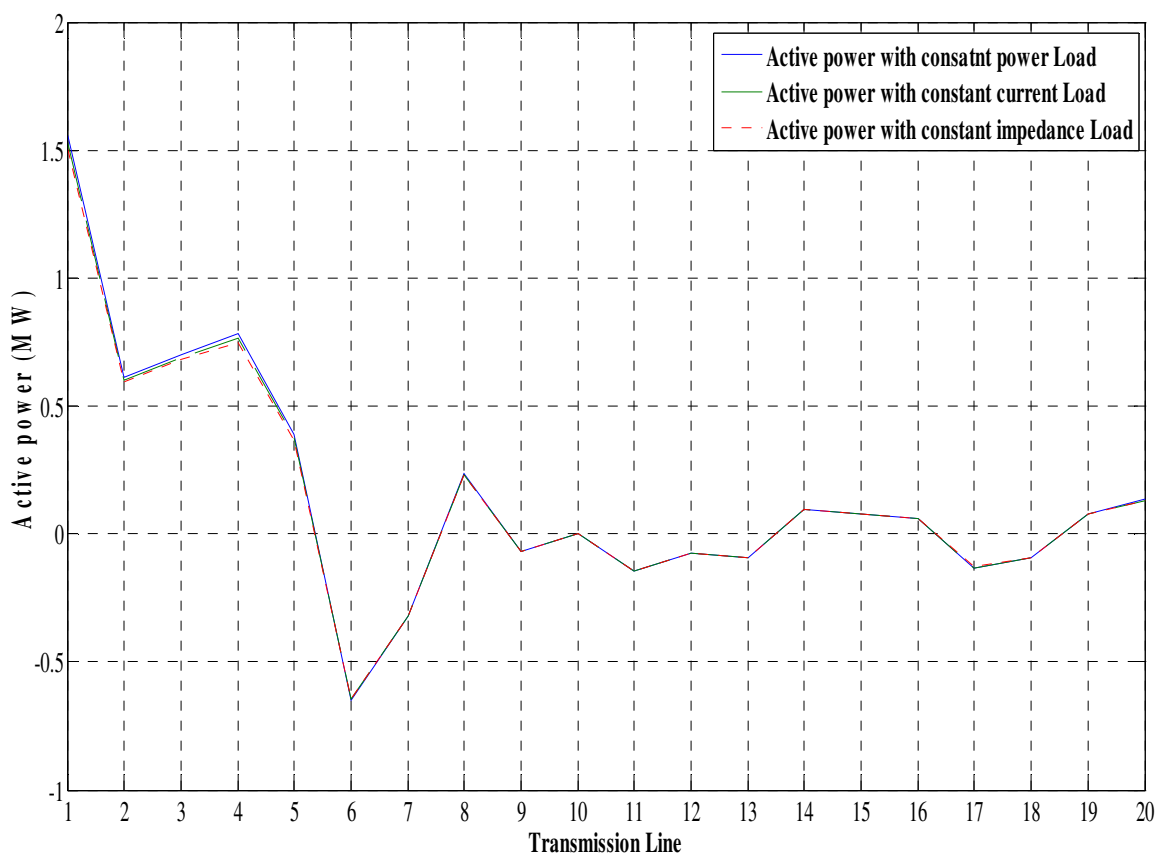

Figure 3. Active power at Line 
Electrical and Electronics Engineering: An International Journal (ELELIJ) Vol 4, No 2, May 2015

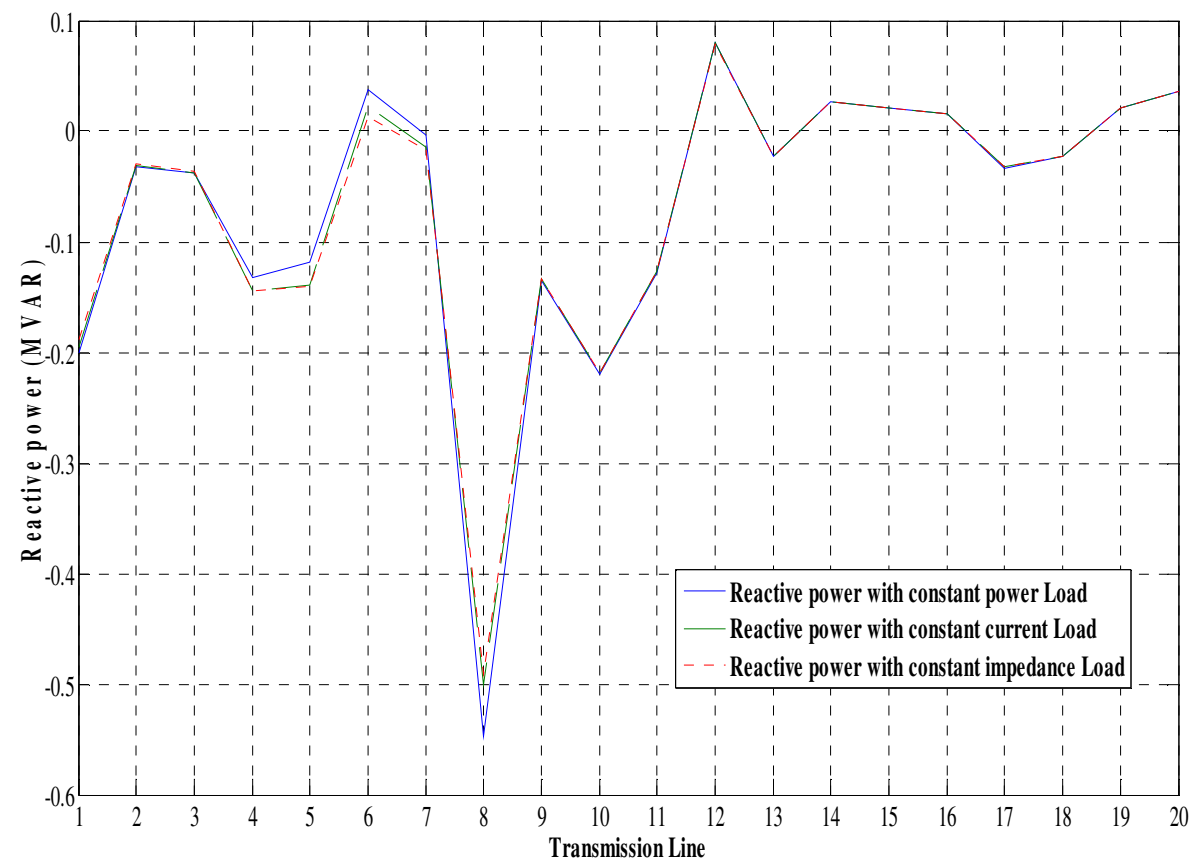

Figure 4. Reactive power at Line

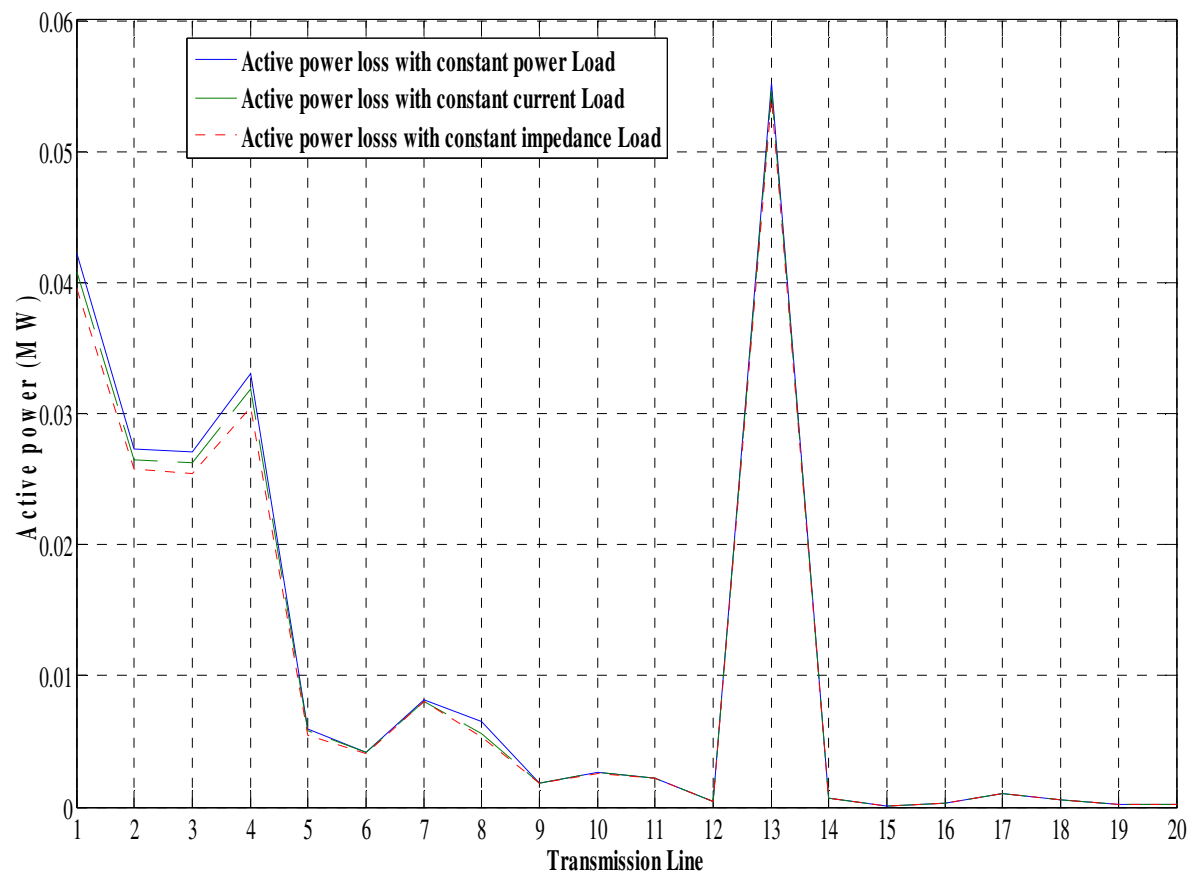

Figure 5. Active Power Losses at Line 


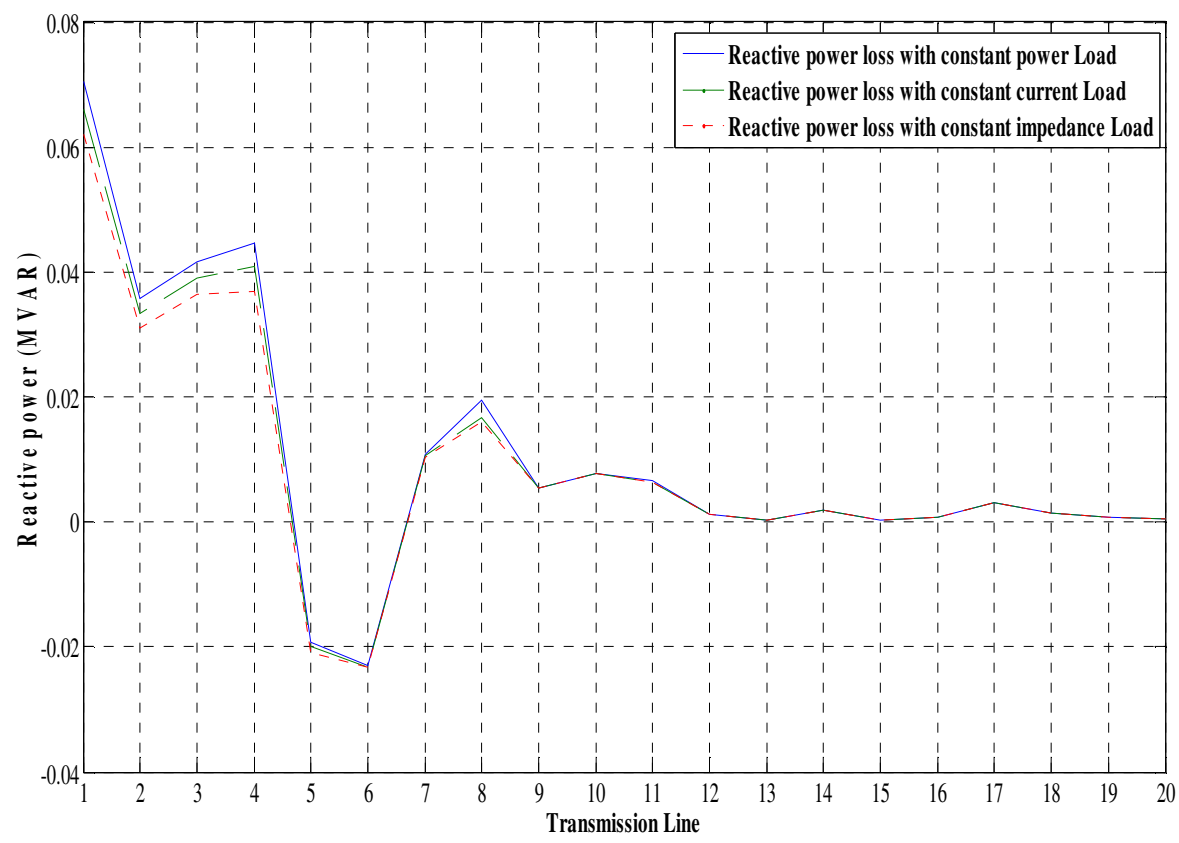

Figure 6. Reactive Power Losses at Line

\section{CONCLUSIONS}

In this paper, load flow analysis has been performed for voltage sensitive loads for a standard 14bus system. The Numerical result for the standard 14 bus network has been presented. As compared with the constant current load, constant impedance loads require additional iteration to obtain the solution. So the load flow analysis with the voltage sensitive loads is more accurate than those for the constant power load.

\section{REFERENCES}

[1] R.B.Shipley, introduction to matrices and power system, New York; wiley 1976.

[2] G.W.Stagg., A.H.EI Abbiad. 'Computer method in power system analysis'. Mc Graw hill, 1968.

[3] BERG, G.J., and KAR, A.K.: 'Model representation of power system loads'. Proceedings of 1971 Power Industry Computation Conference, pp. 153-162, 1971 IEE proceedings, Vol. 136, Pt. C, No. 5, September 1989.

[4] CEA Working Group Report: 'Load modelling techniques and practice'. Engineering and Operating Division Meeting, Quebec City, March 1980.

[5] CEA Working Group Report: 'Monitoring of loads and determination of load models at Ontario hydro'. Spring Meeting 1980.

[6] EL-HAWARY, M.E.: 'Power system load modelling and incorporation in load flow solutions'. Proceedings of the Third Large Systems Symposium, University of Calgary, June 1982.

[7] IEEE Committee Report: 'System load dynamic simulation, effects and determination of load constants', IEEE Trans., 1973, PAS-92

[8] IEEE Working Group Report: 'The effect of frequency and voltage on power system loads'. Paper 31 CP66-64, IEEE Winter Meeting, New York 1966.

[9] ILICETO, F., CEYHAN, A., and RUCKSTUHL, G.: 'Behavior of loads during voltage dips encountered in stability studies’, IEEE Trans., 1972, PAS-91, pp. 247Ck2479. 
[10] MURTY, P.S.R.: 'Load modelling for power flow solutions', IEE Journal (India), July 1977.

[11] SABIR, S.A.Y.: 'Remote load data acquisition for modelling of power systems loads'. Internal Report, Ontario Hydro, September 1977.

[12] SRINIVASAN, K., NGUYEN, C.T., and ROBICHAUD, Y.: 'Online load behavior modelling from natural variations'. Paper A 78-0440, IEEE Winter Power Meeting, New York, 1978.

[13] SABIR, S.A.Y., and LEE, D.C.: 'Dynamic load models derived from data acquired during system transients', IEEE Trans., 1982, PAS- 101, pp. 3365-3372. IEE proceedings, Vol. 136, Pt. C, No. 5, September 1989.

[14] NGUYEN, C.T., PANNETON, J.G., ROBICHAUD, Y., ST.JACQUES, A., and SRINIVASAN, K.: 'Load characteristics and stability of the Hydro Quebec System', IEEE Trans., 1980, PAS-99,

[15] General Electric Company: 'Determining load characteristics for transient performance'. EPRI Final Report RP-849-1. March 1981.

[16] University of Texas at Arlington: 'Determining load characteristics for transient performance'. EPRI Final Report RP 849-3, May 1979.

[17] CONCORDIA, C., and IHARA, S.: 'Load representation in power system stability studies', IEEE Trans., 1982, PAS-101.

[18] BRICKELL, M.R.: 'Simulation of staged tests in the Ontario Hydro Northwestern Region'. Proceedings of 1979 PICA, Cleveland.

[19] VAAHEDI, E., EGKADY, M., LIBAQUE-ESAINE, J.A., and CARVALHO, V.F.: 'Load models for large scale stability studies from end user consumption', IEEE Trans., 1987, PWRS-2, pp.864-871.

[20] DIAS, L.G.: 'Load modelling and incorporation in load flow studies'. MASc. Thesis, Technical University of Nova Scotia, 1985.

[21] EGHAWARY, M.E., and DIAS, L.G.: 'Incorporation of load models in load flow studies: form of model effects', IEE Proc. C, Gener. Trans. \& Distrib., 1987,134, (1), pp. 27-30.

[22] EL-HAWARY, M.E., and DIAS, L.G.: 'Selection of buses for detailed modelling in load flow studies', Electr. Mach. Power Syst., 1987, 12, pp. 83-92.

[23] EI- Hawary, M.E., and Dias, L.G.: 'Incorporation of load models in load - flow studies: from of model effect', IEE Proc. C, Gen. Trans. \& Distrib., 1987,134,(1),pp. 27-30.

[24] Murty, P.S.R. 'Load modelling for power flow solution', J.Inst.Eng.(India) Electr. Eng. Div., 1977, 58, pp.162-165.

\section{AUTHORS}

Nitesh Kumar Lal received his BE degree in Electrical and Electronics Engineering from Rajiv Gandhi Technical University, Bhopal (M.P).He currently pursuing M.Tech degree in Power system from Radharaman Engineering College Bhopal under Rajiv Gandhi Technical University, Bhopal (M.P) India.

Samina. E. Mubeen received her B.E degree in Electrical Engineering from Ravishankar University, Raipur, M.Tech degree in Heavy electrical equipments from Rajiv Gandhi Technical University Bhopal, and $\mathrm{PhD}$ in Power system from Maulana Azad National Institute of Technology, Bhopal. Her field of work is application of FACTS devices in transmission network. She has number of Publications in reviewed journal. At present she is Head of Department of Electrical and Electronics in REC, Bhopal under Rajiv Gandhi

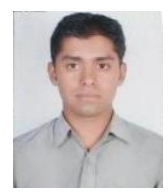
Technical University, Bhopal (M.P) India. 